\title{
Amniotic band syndrome at 14 weeks of gestation: a case report and literature review
}

\author{
Lalitha $\mathbf{N}^{1} *$, Reena Abraham ${ }^{1}$, Umamaheswari $\mathbf{G}^{2}$ \\ ${ }^{1}$ Department of Obstetrics \& Gynaecology, PSG Institute of Medical Sciences \& Research, Coimbatore-641004, Tamil \\ Nadu, India \\ ${ }^{2}$ Department of Pathology, PSG Institute of Medical Sciences \& Research, Coimbatore-641004, Tamil Nadu, India
}

Received: 29 September 2014

Accepted: 22 October 2014

\section{*Correspondence:}

Dr. Lalitha N,

E-mail: lalithanatarajan@yahoo.com

Copyright: $\odot$ the author(s), publisher and licensee Medip Academy. This is an open-access article distributed under the terms of the Creative Commons Attribution Non-Commercial License, which permits unrestricted non-commercial use, distribution, and reproduction in any medium, provided the original work is properly cited.

\begin{abstract}
Amniotic band syndrome comprises of a group of congenital anomalies involving the limbs, trunk, head and face characterised by asymmetry of involvement and varying severity. While mild variants have a good prognosis with normal life expectancy, severe cases may be incompatible with life. It is sporadic in occurrence with many theories postulated towards the pathogenesis. We report a case of amniotic band syndrome diagnosed at 14 weeks gestation in a 22 year old low risk primigravida-the foetus was seen as an amorphous mass with multiple anomalies, confirmed by autopsy. While early ultrasound helped detect lethal anomalies, correlation with autopsy provided an insight into possible disruptions in early foetal development leading to the various anomalies.
\end{abstract}

Keywords: Amniotic band syndrome, Amnion rupture sequence, Prenatal diagnosis

\section{INTRODUCTION}

Prenatal detection of foetal anomalies is a challenge to the obstetrician and the sonologist alike. With the advent of high resolution equipment, foetal anomalies are being detected at an earlier gestational age. The foetal medicine specialist is closely aided by the foetal pathologist in unravelling the mysteries of these anomalies..$^{2-5}$ We present a case of amniotic band syndrome detected at 14 weeks which was terminated and autopsy was done. The autopsy report confirmed ultrasound findings besides providing elaborate morphological features of the condition.

Amniotic band syndrome is a group of sporadic congenital anomalies of varying severity involving limbs, craniofacial region or trunk. The incidence ranges widely from 1 in 1200 to 1 in 15000 depending on the criteria used. Synonyms for this spectrum of disorders include amniotic disruption sequence, Amniotic Deformity
Adhesions and Mutilation (ADAM) complex, Limb Body Wall Complex (LBWC). ${ }^{1}$

\section{CASE REPORT}

A 22 year old primigravida, conceived spontaneously after a non-consanguineous marriage, presented at 14 weeks of gestation when the ultrasound showed a severely malformed foetus as an amorphous mass with cardiac activity in the left horn of a bicornuate uterus. On detailed ultrasound examination the foetus was found to have exencephaly, scoliosis of spine, amputation of the lower limbs and thoracoabdominal schisis with the amniotic strands seen attached to the foetus.

After obtaining informed consent, the pregnancy was terminated and the foetus sent for autopsy. The autopsy showed the foetus to have acrania, anophthalmia and anotia (right), cleft lip, scoliosis, abdominoschisis, limb defects and an extremely short umbilical cord. The diagnosis of limb body wall complex with ruptured 
amnion was made. The vault of the skull and brain were absent. The base of the skull was covered by a thick white membrane that connected it to the placenta. On division this appeared to be the wall of a collapsed cavity with few strands and a white opaque nodule. The right eye, ear and nose were absent. The left eye and ear were hidden by the membrane. The left palpebral fissure was not formed. Left external ear was well formed; mouth had a wide cleft in the upper lip, tongue, palate and both jaws were normal. The neck was extremely short, spine was curved; ribs were present on the left and absent on the right side. Only a layer of soft tissue covered the heart and lungs which lay anterior to the spine. The anterior abdominal wall was absent. The umbilical cord was extremely short and a small sac was seen at its insertion into the placenta-the ruptured amnion. A white thin membrane extended between the surface of the placenta and the lower border of the liver and lower right chest. The pharynx, oesophagus, stomach, pancreas, small and large intestines were normal. The liver was ovoid; spleen, ureters, bladder, internal genitalia were not identified. Ovoid pale brown nodules were present on either side of the spine which could not be differentiated as a kidney or adrenal. Due to the extreme curvature of the spine, the chin lay close to the pelvis. The right upper limb was distorted with a short arm, forearm and barely discernible digits; the left arm, forearm and digits were normal. The left lower limb was superior to the right, flexed at the knee and adducted at the ankle with 6 well-formed digits. The right lower limb was flat and thin, flexed at the knee, dorsiflexed at the ankle with 4 digits.

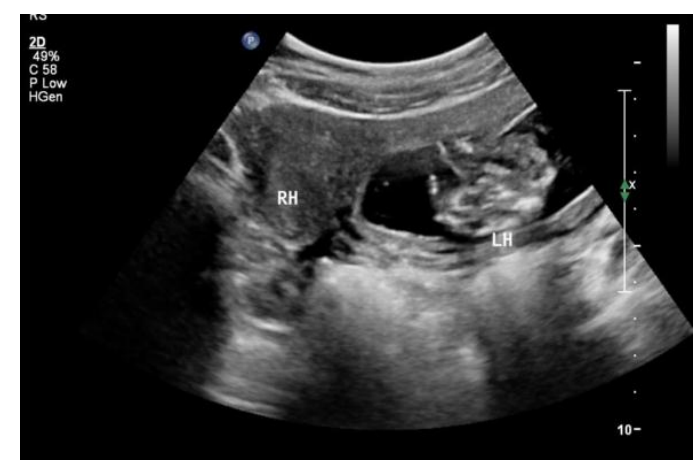

Figure 1: USG image showing foetus in the left horn.

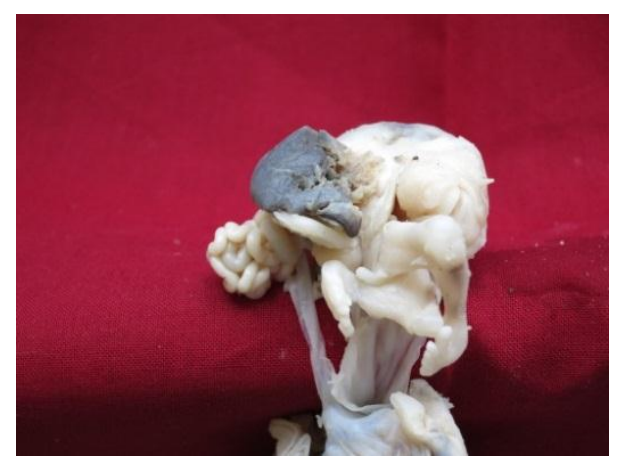

Figure 2: Autopsy picture showing liver outside the abdomen.

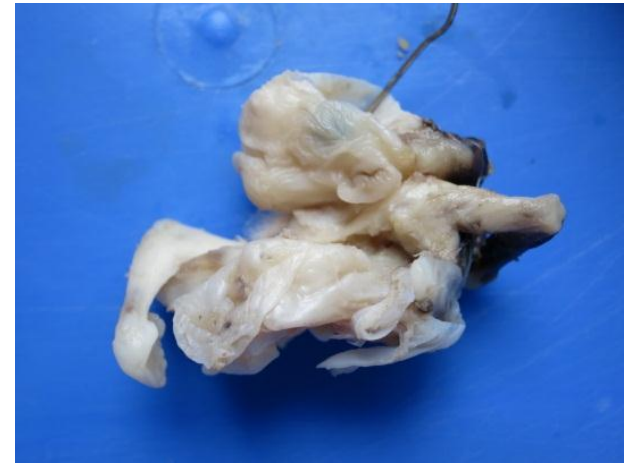

Figure 3: Acrania.

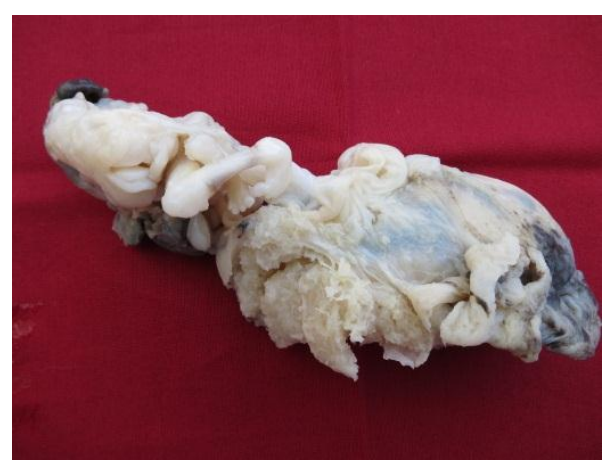

Figure 4: Limb Anomalies.

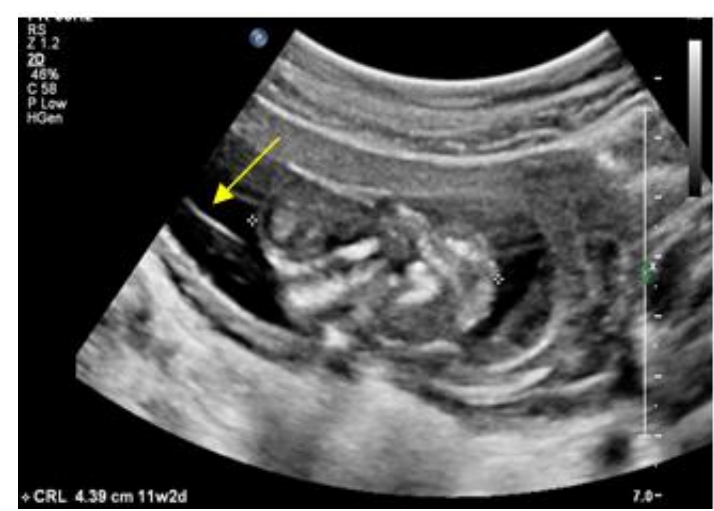

Figure 5: Amniotic strands seen attached to the foetus.

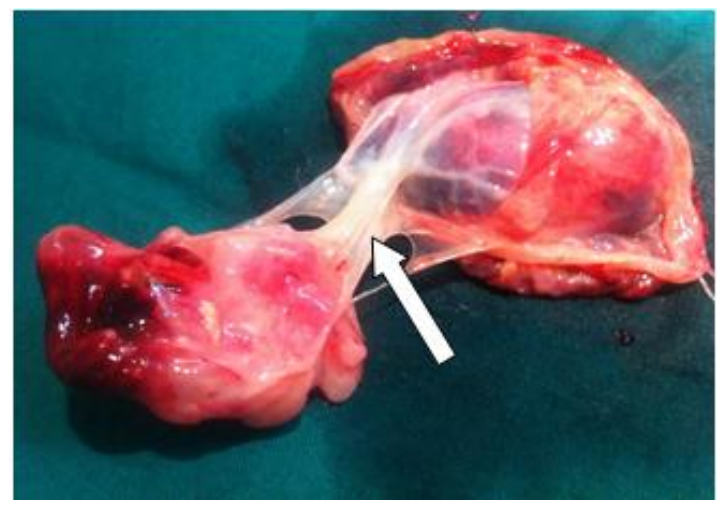

Figure 6: Amniotic strands seen attached to the foetus. 


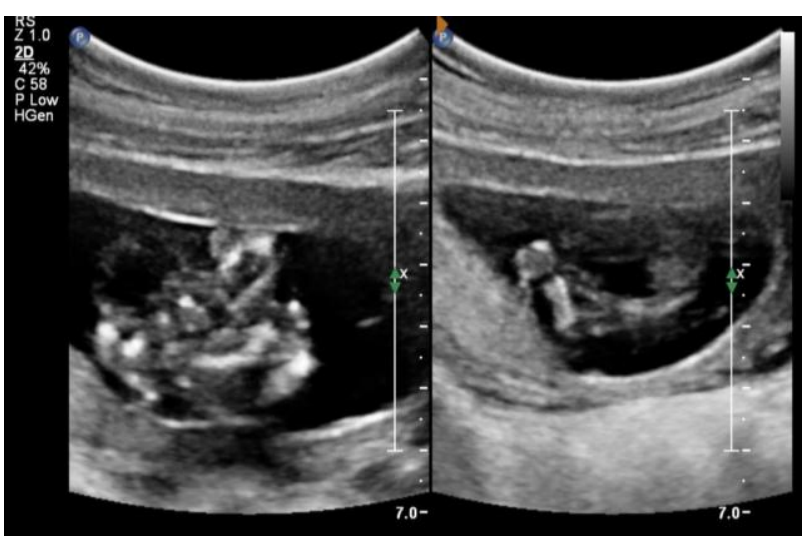

Figure 7: Ultrasound image of the foetus showing limb anomalies.

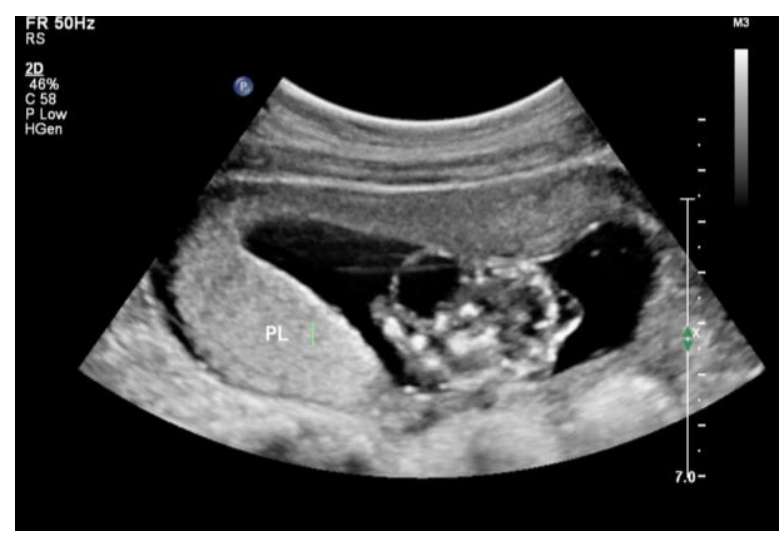

Figure 8: Ultrasound image of the foetus showing absent abdominal wall.

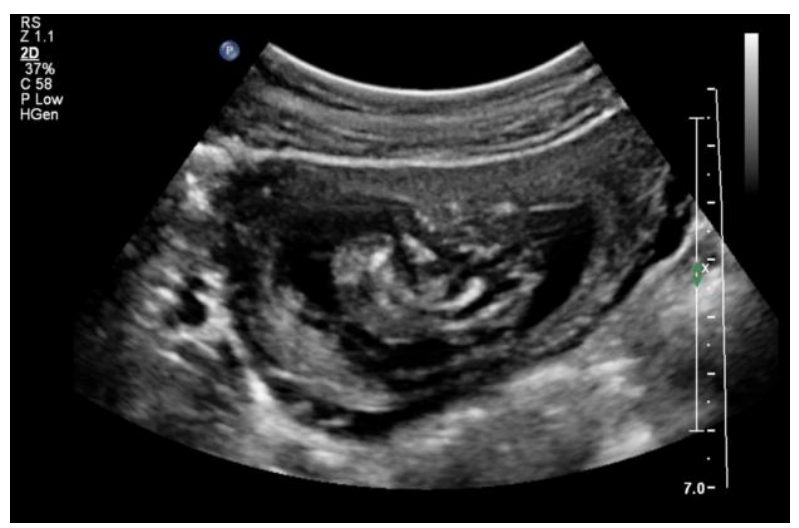

Figure 9: Ultrasound image of the foetus showing malformations.

\section{DISCUSSION}

Amniotic band syndrome comprises of a spectrum of anomalies which vary in severity. The triad of ABS includes amnion-denuded placenta; foetal attachment or entanglement by amniotic remnants; foetal deformation, malformation and/or disruption. ${ }^{6-9}$ There are many theories proposed to explain the occurrence of this syndrome. Streeter's $(1930)^{10}$ intrinsic hypothesis postulates a disruption in embryogenesis at the time of formation of the germ disk whereas Torpin's (1965) extrinsic hypothesis suggested that the birth defects are caused by the primary rupture of amnion early in gestation. Moerman et al. ${ }^{11}$ (1992) proposed that the ABS is a collection of three distinct lesions-constrictive tissue bands, amniotic adhesions and the more complex limbbody wall complex. They suggested that adhesive amniotic bands were morphologically and pathogenetically different from the constrictive bands. Where the former caused severe defects like encephalocele and facial clefts, the latter are linked to limb anomalies. ${ }^{12,13}$

The type of anomalies depends on the stage of embryonic development and the severity of the disruption. The various disorders are classified into 4 categories based on the timing of the disruption and the resulting anomalies. $^{14,15}$ Group I comprises of severe anomalies like anencephaly, craniofacial clefts and limb body wall complex, which are uniformly fatal in the neonatal period; the timing of disruption being in the early embryonic period - <4 weeks post conception(pc) or 3-6 weeks pc. Group II comprises of clefts, CHD, limb reduction, the insult occurring in the midembryonic period (4-7 weeks pc). Group III comprises of oligohydramnios and Pierre-Robin sequence (late embryonic to early foetal period - 7-12 weeks pc). Group IV comprises of limb amputation and constriction bands (after 9 weeks pc).

Kalousek et al. ${ }^{16}$ divide the amnion defects into the Limb Body Wall Complex (LBWC) caused by an early defect of the amniotic sac, and the amnion rupture sequence caused by amniotic bands. They also reported that the incidence of amnion rupture sequence is much higher in pre-viable spontaneous abortions than in term foetuses, indicating that most cases are spontaneously aborted.

Various studies and case reports point to different etiological factors ${ }^{17,18}$ including maternal drug abuse, cigarette smoking, unplanned pregnancy, anorexia, hyperthermia, young maternal/paternal age, dietary glycaemic index, abdominal trauma, infections, amniocentesis etc. which have been implicated in the causation of ABS.A human homologue of the mouse disorganisation gene(Ds) has been proposed as a cause of some cases of amnion disruption by a two-hit mechanism $^{19}$ (the gene is yet to be identified). Some cases of amniotic band like anomalies associated with cleft lip and palate may represent mutation in the genes Disorganization p63 or IRF6.There have been reported association with underlying disease $\mathrm{e}^{20}$ - Ehler Danlos syndrome or osteogenesis imperfecta. The malformations of ABS should be distinguished from those occurring in a syndromic setting by the fact that the clefts do not follow anatomic lines of closure and the lesions are asymmetrical. This is important since most cases of Amniotic band syndrome are sporadic and there is no risk of recurrence in subsequent pregnancies. 


\section{CONCLUSION}

Foetal anomalies bring with them multiple responsibilities to the obstetrician, that of identifying the anomalies in the foetus, prognosticating about them to the parents, terminating the pregnancy in appropriate situations and counselling the parents on the possibility of recurrence of the anomaly in subsequent pregnancies. Prenatal ultrasound examination helps us in detecting these anomalies in early gestation. Foetal autopsy provides crucial inputs on the foetal pathology.

\section{ACKNOWLEDGEMENTS}

We acknowledge the services of Dr. Ammu Sivaraman, Emeritus Professor of Department of Pathology, PSGIMSR in performing foetal autopsy.

\section{Funding: No funding sources}

Conflict of interest: None declared

Ethical approval: Not required

\section{REFERENCES}

1. Chen CP. Prenatal diagnosis of limb body wall complex with craniofacial defects, amniotic bands, adhesions and upper limb deficiency. Prenat Diagn. 2001;21:418-24.

2. Cheschair NC, Reibaueur PJ. A comparative study of prenatal diagnosis and perinatal autopsy. J Ultrasound Med. 1994;13:451-6.

3. Johns N, Al-Salti W, Cox P, Kilby MD. A comparative study of prenatal ultrasound findings and postmortem examination in a tertiary referral centre. Prenat Diagn. 2004;24:339-46.

4. Sankar VH, Phadke SR. Clinical utility of fetal autopsy and comparison with prenatal ultrasound findings. J Perinatol. 2006;26:224-9.

5. Enid Gilbert-Barness, Raj P. Kapur, Luc Laurier Oligny, Joseph R. Siebert. Foetal anomalies. In: Enid Gilbert-Barness, Raj P. Kapur, Luc Laurier Oligny, Joseph R. Siebert, eds. Potter's Pathology of the Foetus, Infant and Child. 2nd ed. US: MosbyElsevier; 2007.

6. Kulkarni ML, Gopal PV. Amniotic band syndrome. Indian Paediatr. 1990;27:471-6.

7. Higginbottom MC, Jones KL, Hall BD. The amniotic band disruption complex: timing of amniotic rupture and variable spectra of consequent defects. J Paediatr. 1979;96:544-9.
8. Lockwood C, Ghidini A, Romero R, Hobbins JC. ABS: reevaluation of its pathogenesis. Am J Obstet Gynaecol. 1989;160:1030-3.

9. Seeds JW, Cefalo RC, Herbert WNP. Amniotic band syndrome. Am J Obstet Gynaecol 1982;144:243-8.

10. Bamforth JS. Amniotic band sequence: Streeter's hypothesis reexamined. Am J Med Genet. 1992;44:280-7.

11. Moerman P, Fryns JP, Vandenberghe K, Lauweryns JM. Constrictive amniotic bands, amniotic adhesions, and limb-body wall complex: discrete disruption sequence with pathogenetic overlap. Am J Med Genet. 1992;42:470-9.

12. Diana W. Bianchi, Timothy M. Crombleholme, Mary E. D' Alton, Fergal Malone. Limb anomalies. In: Diana W. Bianchi, Timothy M. Crombleholme, Mary E. D' Alton, Fergal Malone, eds. FoetologyDiagnosis and Management of the Foetal Patient. 2nd ed. New York: McGraw Hill; 2010.

13. Cromblehome TM. The fetus with amniotic band syndrome, the unborn patient. In: Harrison MR, Evans MI, Adzick NS, Holzgreve W, eds. The Art and Science of Fetal Therapy. 3rd ed. Philadelphia, PA: WB Saunders; 2001: 489-502.

14. Ho DM, Liu HC. The ABS: report of two autopsy cases and review of the literature. Clin Med J. 1987;39:429-36.

15. Huang CC, Eng HL, Chen WJ. Amniotic band syndrome: report of two autopsy cases. Chang Gung Med J. 1995;18: 371-7.

16. Kalousek DK, Fitch N, Paradice BA. Amnion defects. In: Kalousek DK, Fitch N, Paradice BA, eds. Pathology of the Human Embryo and the Previable Fetus. 1st ed. An Atlas. New York: Springer-Verlag; 1990.

17. Ossipoff V, Hall BD. Etiologic factors in the ABS: a study of twenty-four patients. Birth Defects. 1977;13:117-21.

18. Cignini P, Giorlandino C, Padula F, Dugo N, Cafà EV, Spata A. Epidemiology and risk factors of Amniotic band syndrome or ADAM sequence. J Perinat Med. 2012;6(4):59-63.

19. Donnai D, Winter RM. Disorganisation: a model for early amnion rupture? J Med Genet. 1989;26:421-5.

20. Young ID, Lindenbaum RH, Thompson EM, Pembrey ME. Amniotic bands in connective tissue disorders. Arch Dis Child. 1985;60:1061-3.

DOI: $10.5455 / 2320-1770$. ijrcog20141257

Cite this article as: Lalitha N, Abraham R,

Umamaheswari G. Amniotic band syndrome at 14 weeks of gestation: a case report and literature review. Int J Reprod Contracept Obstet Gynecol 2014;3:1142-5. 